\title{
HIGUCHI MODEL APPLIED TO IONS RELEASE FROM HYDROXYAPATITES
}

\author{
AURORA MOCANUa, PETRE T. FRANGOPOL ${ }^{\&}$, REKA BALINT ${ }^{a}$, \\ OANA CADAR ${ }^{\mathrm{b}}$, IULIA MARIA VANCEA ${ }^{\mathrm{a}}$, ROZALIA MINTĂU ${ }^{\mathrm{a}}$, \\ OSSI HOROVITZ ${ }^{a}$, MARIA TOMOAIA-COTISEL ${ }^{\mathrm{a}, \mathrm{c}^{*}}$
}

\begin{abstract}
In this study, the ions release of physiological elements from pure stoichiometric hydroxyapatite, HAP, and from multi-substituted hydroxyapatite, ms-HAPs, containing $1.5 \% \mathrm{Mg}, 0.2 \% \mathrm{Zn}, 0.2 \% \mathrm{Si}$ and $5 \% \mathrm{Sr}$, noted $\mathrm{HAPC}-5 \% \mathrm{Sr}$, and from HAPc- $10 \% \mathrm{Sr}$, in water and in simulated body fluid, SBF, was studied by inductively coupled plasma optical emission spectrometry, ICP-OES, both in static and simulated dynamic regimes. The HAP and ms-HAP nanoparticles, NPs, were prepared by wet chemical precipitation and lyophilized powders were physicochemical characterized as presented elsewhere. The in vitro cations and anions release mechanism was investigated by applying a modified Higuchi model, which fits well the experimental results, particularly for simulated dynamic conditions. The predominant role of diffusion in the release of ions from the hydroxyapatites was confirmed. The sustained ions release from these nanomaterials recommends the investigated ms-HAPs for therapeutic applications.
\end{abstract}

Keywords: multi-substituted hydroxyapatites; ions release; static conditions, simulated dynamic conditions; Higuchi model

\section{INTRODUCTION}

Hydroxyapatite, HAP, and multi-substituted hydroxyapatites, ms-HAPs are frequently used as bone substitutes [1-9]. As physiological elements $\mathrm{Mg}$, $\mathrm{Zn}, \mathrm{Sr}$ and $\mathrm{Si}$ were employed due to their role in bone regeneration $[10,11]$ and multiple biomedical applications in orthopedy and in stomatology [12-16]

\footnotetext{
a Babeş-Bolyai University, Faculty of Chemistry and Chemical Engineering, Research Center of Physical Chemistry, 11 Arany Janos Str., RO-400028, Cluj-Napoca, Romania.

b INCDO INOE 2000, Research Institute for Analytical Instrumentation, 67 Donath Str., RO-400293 Cluj-Napoca, Romania.

c Academy of Romanian Scientists, 3 Ilfov Str., RO-050044, Bucharest, Romania.

\& Deceased on December 11, 2020.

*Corresponding author: mcotisel@gmail.com.
} 
as coatings on metallic implants for enhanced osseointegration in the fracture healing. The structure of ms-HAP nanomaterials is the unchanged HAP structure, as demonstrated previously [2, 17-19] by complimentary methods XRD, SEM, AFM, BET, IR, Raman [11], as well TG, DTG, DTA and DSC showing a superior thermal stability $[2,7]$.

Hydroxyapatite and other calcium phosphates were also used as carriers for various drugs, and the drug release in water and physiological liquids was investigated [20-26]. However, HAPs powders, containing physiological elements, Mg, Zn, Si and Sr, have not been actively studied for simultaneously ions release in immersion liquids. One reason for the lack of research is that ions release requires extended investigation in time for evaluation of the ions release profile which might be related with the optimal therapeutic effect of these nanomaterials [11, 27, 28].

The behavior of synthesized stoichiometric hydroxyapatite (HAP) $\mathrm{Ca}_{10}\left(\mathrm{PO}_{4}\right)_{6}(\mathrm{OH})_{2}$ and of two multi-substituted hydroxyapatites (ms-HAPs), both containing $1.5 \mathrm{wt} \% \mathrm{Mg}, 0.2 \mathrm{wt} \% \mathrm{Zn}, 0.2 \mathrm{wt} \% \mathrm{Si}$ and different $\mathrm{Sr}$ amounts: HAPc- $5 \% \mathrm{Sr}$, respectively HAPc-10\%Sr when immersed in water and in simulated body fluid (SBF) was recently investigated $[11,27]$. The theoretical formulas for the ms-HAP materials are: $\mathrm{Ca}_{8.76} \mathrm{Mg}_{0.63} \mathrm{Zn}_{0.03} \mathrm{Sr}_{0.58}\left(\mathrm{PO}_{4}\right)_{5.93}\left(\mathrm{SiO}_{4}\right)_{0.07}(\mathrm{OH})_{1.93}$ for $\mathrm{HAPc}-5 \% \mathrm{Sr}$ and $\mathrm{Ca}_{8.12} \mathrm{Mg}_{0.65} \mathrm{Zn}_{0.03} \mathrm{Sr}_{1.20}\left(\mathrm{PO}_{4}\right)_{5.93}\left(\mathrm{SiO}_{4}\right)_{0.07}(\mathrm{OH})_{1.93}$ for HAPc-10\%Sr. The release of $\mathrm{Ca}^{2+}, \mathrm{Mg}^{2+}, \mathrm{Sr}^{2+}$, as well as of $\mathrm{P}$ (phosphate) in water and the variation of ions content in SBF in contact with soaked HAPs was measured using inductively coupled plasma optical emission spectrometry (ICP-OES). $\mathrm{Zn}^{2+}$ and silicate ions could not be detected in the solutions, since they were under the detection limit of ICP-OES. A static method was applied, where the HAP samples were maintained in the immersion liquid in closed flasks for different time frames, from 1 to 90 days, and a simulated dynamic method, when the immersion liquid was changed daily with a fresh one, for 7 days.

Some conclusions about the release kinetics were obtained by applying the Korsmeyer-Peppas equation to our results [11, 27] when a complex mechanism, variable in time, including diffusion, but also incongruent dissolution effects was evidenced. For the samples soaked in SBF, only strontium release can be considered, since in SBF calcium, phosphate and magnesium ions are present, and an uptake of these ions takes place on the solid HAPs, with formation of new apatite. Therefore in the case of these ions the release in SBF is counteracted by their deposition, which can even overcome the release.

In order to better understand the role of diffusion and dissolution, we decided to further explore the release mechanism with a different mathematical model. The Higuchi model [29-31] was largely applied and compared with other 
models mostly for the release of drugs from polymeric matrices [32-37], but also from inorganic matrices, particularly hydroxyapatites and other calcium phosphates [38-40]. It is based on Fickian diffusion, so it should work when inner diffusion of ions from the particle to the surrounding liquid is the rate determining step and the released species is uniformly distributed in a homogeneous matrix [38]. Then, the released amount of a species should be proportional to the square root of time. The simplest form of the Higuchi equation is:

$$
M_{t}=k_{H} t^{1 / 2}
$$

where $M_{t}$ is the cumulative ions release at time t. The Higuchi release rate constant $\mathrm{k}_{\mathrm{H}}$ is determined for given conditions both by characteristics of the solid matrix and by the characteristics of the released species.

\section{RESULTS AND DISCUSSION}

For a verification of the role of inner diffusion in the ion release from HAPs, the applicability of the Higuchi equation (1) was tested. The ion release profile from HAP, HAPc- $5 \% \mathrm{Sr}$ and $\mathrm{HAPc}-10 \% \mathrm{Sr}$, both noncalcined and calcined, is represented in Figure 1 against the square root of time $\left(\mathrm{t}^{1 / 2}\right)$, with time measured in days $\left(\mathrm{d}^{1 / 2}\right)$ for 90 days in static conditions. In Figure 2 the cumulated ion release is represented against time ${ }^{1 / 2}\left(\right.$ days $\left.^{1 / 2}\right)$ for 7 days in simulated dynamic conditions (replacement of the immersion liquid after each day).

It is evident from Figures 1 and 2 that the first point (for day 0 ) is an outlier. The regression lines for the linearization $M_{t}=f\left(t^{1 / 2}\right)$ do not pass through the origin of coordinates, in agreement with the finding that diffusion is not the main process in the early stages of ion release. Therefore a modified form of equation (1) was tried:

$$
M_{t}=a+K t^{1 / 2}
$$

where $M_{t}$ is the cumulative ions release at time $t$ and $K$ is a release rate constant, which depends both on the characteristics of HAP nanoparticles and on the properties of the released species, but also on the nature of the immersion medium or temperature. Some of the regression lines can be seen in Figure 3 on the example of the noncalcined HAPc-5\%Sr sample, for the release of $\mathrm{Mg}^{2+}$ ions in water and $\mathrm{Sr}^{2+}$ ions both in water and $\mathrm{SBF}$, in static and simulated dynamic conditions.

In Table 1 the parameters of the regression lines according to eq. (2) are given for days 1-90 in static conditions: the y-intercept, a-value, and the release rate constant, $\mathrm{K}$, with their standard errors and the coefficients of determination $\left(r^{2}\right)$. 

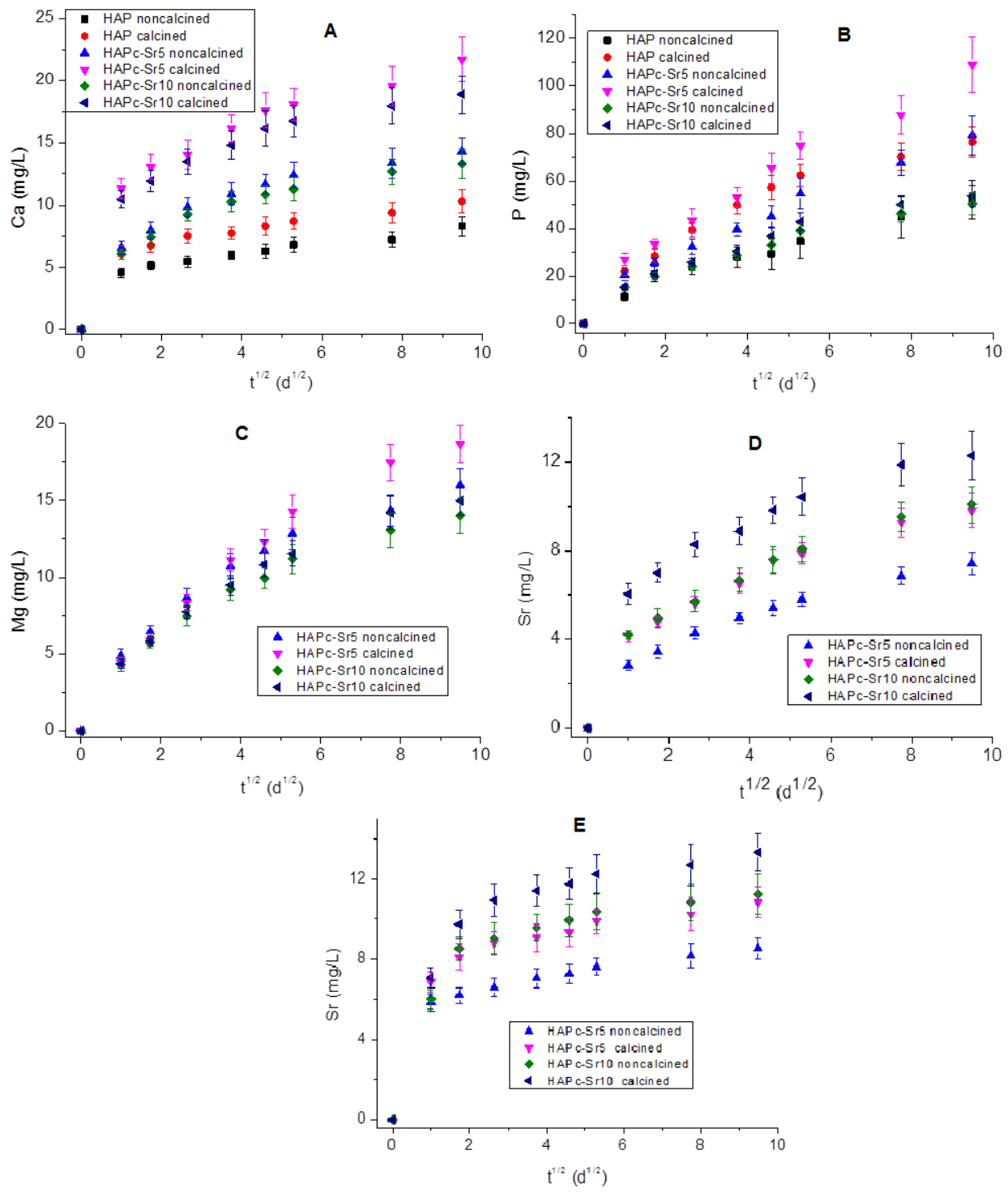

Figure 1. Ion release vs. square root of time (days ${ }^{1 / 2}$ ) for 90 days in static conditions from noncalcined and calcined samples of HAP, HAPc-5\%Sr (HAPc-Sr5) and HAPc-10\%Sr (HAPc-Sr10). Release in water of $\mathrm{Ca}^{2+}(\mathrm{A}), \mathrm{P}$ (phosphate ions, $\mathrm{B}$ ), $\mathrm{Mg}^{2+}(\mathrm{C}), \mathrm{Sr}^{2+}(\mathrm{D})$, and $\mathrm{Sr}^{2+}$ in SBF (E). Vertical bars represent the standard deviations of the measured values. 

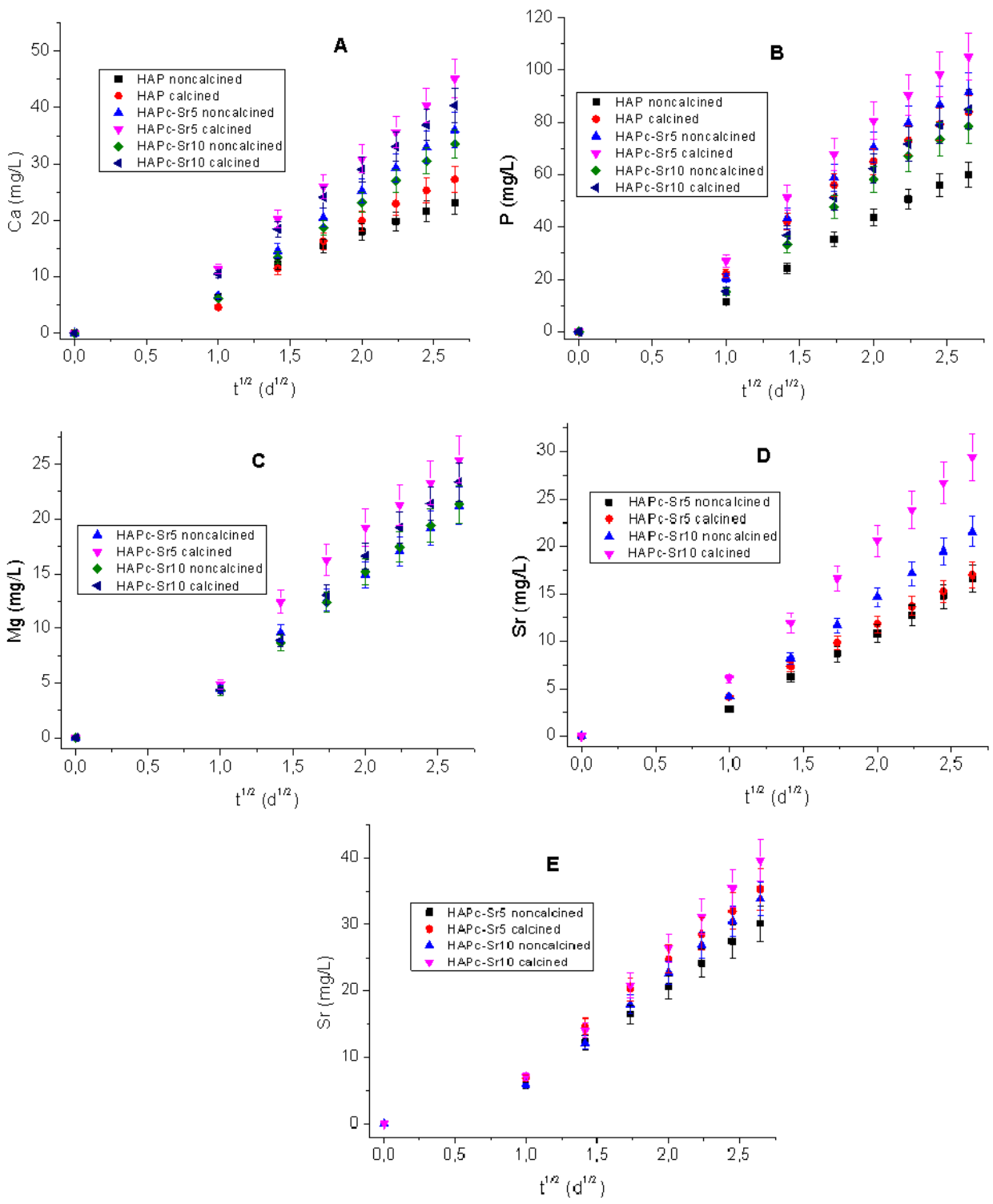

Figure 2. Cumulated ion release vs. time $e^{1 / 2}\left(\right.$ days $\left.^{1 / 2}\right)$ for 7 days in simulated dynamic conditions from noncalcined and calcined samples of HAP, HAPc-5\%Sr (HAPc-Sr5) and $\mathrm{HAPc}-10 \% \mathrm{Sr}(\mathrm{HAPc}-\mathrm{Sr} 10)$. Release in water of $\mathrm{Ca}^{2+}(\mathrm{A}), \mathrm{P}$ (phosphate ions, B),

$\mathrm{Mg}^{2+}(\mathrm{C}), \mathrm{Sr}^{2+}(\mathrm{D})$, and $\mathrm{Sr}^{2+}$ in SBF (E). Vertical bars represent the standard deviations of the measured values. 

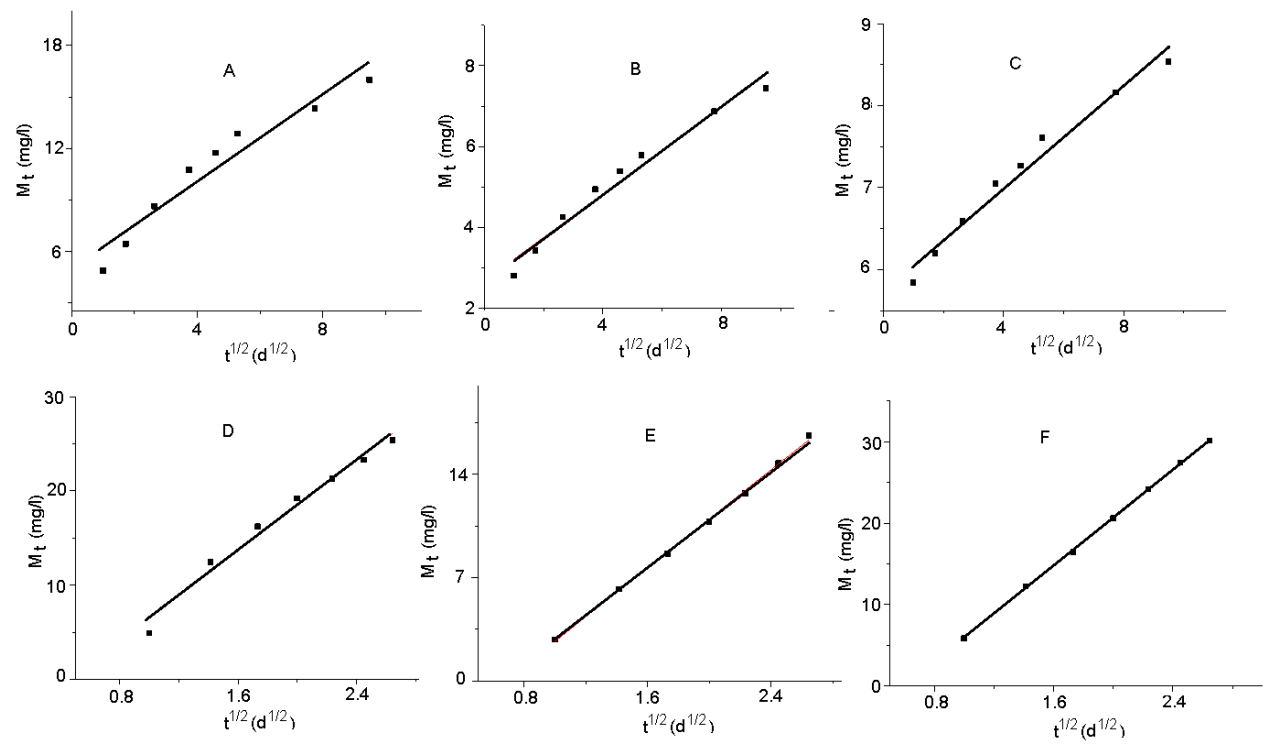

Figure 3. Regression lines for ions release from noncalcined HAPc-5\%Sr (HAPc-Sr5) of $\mathrm{Mg}^{2+}(\mathrm{A}, \mathrm{D})$ and $\mathrm{Sr}^{2+}(\mathrm{B}, \mathrm{E})$ in water, and of $\mathrm{Sr}^{2+}$ in $\mathrm{SBF}(\mathrm{C}, \mathrm{F})$ in static conditions, for 90 days $(A-C)$, and in simulated dynamic conditions for 7 days (D-F).

The equation (2) applies satisfactory; most $r^{2}$ values are over 0.9 . The Higuchi equation works better for $\mathrm{Ca}$ and $\mathrm{P}$, the main constituents of the HAPs, and best for the unsubstituted HAP. The equation (2) fails for $\mathrm{Sr}$ release from $\mathrm{HAPc}-10 \% \mathrm{Sr}$ in $\mathrm{SBF}$, where ions exchange processes can appear, between $\mathrm{Ca}^{2+}$ and $\mathrm{Mg}^{2+}$ ions from the solution, and $\mathrm{Sr}^{2+}$ ions from the solid sample. However, for days 28-90, the regression lines have determination coefficients of over 0.99 for noncalcined HAPc-10\%Sr and 0.94 for the calcined one. Thus diffusion becomes the major mechanism also in this case for later immersion times, when ion exchange would be expected to slow down.

Generally, the linearity is not strictly maintained through the entire domain of values. For not substituted HAP the highest coefficient of determination is found for the values for days 14-90 of calcium and $P$ release, with a sensibly lower $\mathrm{K}$ value than for the first days. That could mean that after a period of more rapid dissolution, the inner diffusion (characterized by the $t^{1 / 2}$ rate law) becomes preponderant. Higher $r^{2}$ values for the later days of interaction between HAPs and water are observed for most ions and samples, the linearity of the $M_{t}=f\left(t^{1 / 2}\right)$ plots becoming more 
marked, as observed also in Figure 1. For example, for $\mathrm{Ca}^{2+}$ release from noncalcined HAP $\mathrm{r}^{2}=0.997$, from noncalcined HAPc-5\%Sr: 0.999 in days 7-28, from calcined HAPc-10\%Sr over 0.99 in days 21-90; for $P$ from noncalcined HAP $r^{2}=0.99$ for days 14-90. For the substituted HAPs and for the release of $\mathrm{Mg}$ and $\mathrm{Sr}$, the $\mathrm{t}^{1 / 2}$ law seems to be applicable earlier, starting from the first days of immersion in water.

Considering the $\mathrm{K}$ parameter as a measure of the diffusion rate, it appears that the diffusions of $\mathrm{Ca}$ and $\mathrm{P}$ process faster from substituted HAPs than from the unsubstituted one, while for HAPc- $10 \% \mathrm{Sr}$ the rate is lower than for HAPc-5\%Sr. This could be explained by the distortion of the crystal lattice by substitution of $\mathrm{Ca}^{2+}$ with differently sized cations, which favors inner diffusion. On the other hand, the a-values (y-intercepts) can be considered an extrapolation of the ion release at time 0 and a measure of initial solubility. For $\mathrm{Ca}^{2+}$ they are also higher in substituted HAPs, thus confirming the solubility increase by substitution in HAPs [41, 42].

In order to compare the diffusion rates of different cations we have to use $\mathrm{K}$ values calculated in $\mathrm{mmol} \mathrm{L}^{-1} \mathrm{~d}^{-1 / 2}$ instead of $\mathrm{mg} \mathrm{L}^{-1} \mathrm{~d}^{-1 / 2}$ as shown in Table 1. For instance, in calcined samples the values are:

HAPC - 5\%Sr: 0.029 for $\mathrm{Ca}^{2+} ; 0.071$ for $\mathrm{Mg}^{2+} ; 0.0079$ for $\mathrm{Sr}^{2+}$

HAPC-10\%Sr: 0.024 for $\mathrm{Ca}^{2+} ; 0.052$ for $\mathrm{Mg}^{2+} ; 0.0084$ for $\mathrm{Sr}^{2+}$.

Therefore the diffusion rate of $\mathrm{Mg}$ is much higher as for $\mathrm{Sr}$, and also over the value for $\mathrm{Ca}$. This could be due to the lower size of $\mathrm{Mg}^{2+}$ ions (ionic radius $86 \mathrm{pm}$ ) as compared to $\mathrm{Sr}^{2+}(132 \mathrm{pm})$ and $\mathrm{Ca}^{2+}(114 \mathrm{pm})$, and thus to their higher mobility. The a-values (recalculated in $\%$ to the initial content of the element in the sample) indicate also a higher release of $\mathrm{Mg}^{2+}$ ions $(2.49 \%$ from calcined $\mathrm{HAPc}-5 \% \mathrm{Sr}$ and $2.77 \%$ from $\mathrm{HAPc}-10 \% \mathrm{Sr}$ ), as compared with the corresponding values for $\mathrm{Ca}^{2+} ;(0.33 \%$ and $0.35 \%$ respectively), and $\mathrm{Sr}^{2+}(0.76 \%$ and $0.60 \%$ in water, $1.47 \%$ and $0.85 \%$ in $\mathrm{SBF}$ ). This stronger magnesium release from substituted HAPs is known in literature $[43,44]$. It is also worth noting the higher strontium release in SBF than in water, also observed by Beuvelot et al. [45], which can be assigned to the ion exchange with $\mathrm{Ca}^{2+}$ and $\mathrm{Mg}^{2+}$ ions, components of the SBF.

It is interesting that $\mathrm{K}$ values for strontium in SBF are lower than in water (Table 1), while the ion release, as measured by a-values, is higher. The cause should be the interference of ion exchange with the cations present in SBF. The different release rates for different ions determine a different composition of the dissolved material than the original solid one, i.e. an incongruent dissolution of HAPs [11, 46]. 
AURORA MOCANU, PETRE T. FRANGOPOL, REKA BALINT, OANA CADAR, IULIA MARIA VANCEA, ROZALIA MINTĂU, OSSI HOROVITZ, MARIA TOMOAIA-COTISEL

Table 1. Parameters of equation (2) for ions release from HAPs in water and in SBF in static conditions (90 days).

\begin{tabular}{|c|c|c|c|c|c|}
\hline Ion & Sample & $\begin{array}{l}\text { Me- } \\
\text { dium }\end{array}$ & $\begin{array}{c}a \\
(\mathrm{mg} / \mathrm{L})\end{array}$ & $\begin{array}{c}K \\
\left(m g L^{-1} d^{-1 / 2}\right)\end{array}$ & $r^{2}$ \\
\hline $\mathrm{Ca}^{2+}$ & $\begin{array}{l}\text { HAP noncalcined } \\
\text { HAP calcined } \\
\text { HAPc- } 5 \% \text { Sr noncalcined } \\
\text { HAPc- } 5 \% \text { Sr calcined } \\
\text { HAPc- } 10 \% \text { Sr noncalcined } \\
\text { HAPc- } 10 \% \text { Sr calcined }\end{array}$ & Water & $\begin{array}{l}4.41 \pm 0.14 \\
6.13 \pm 0.13 \\
7.01 \pm 0.61 \\
11.2 \pm 0.5 \\
6.5 \pm 0.6 \\
10.7 \pm 0.6\end{array}$ & $\begin{array}{l}0.405 \pm 0.026 \\
0.445 \pm 0.025 \\
0.86 \pm 0.11 \\
1.16 \pm 0.10 \\
0.80 \pm 0.11 \\
0.96 \pm 0.12\end{array}$ & $\begin{array}{l}0.9723 \\
0.9779 \\
0.8868 \\
0.9484 \\
0.8900 \\
0.9069\end{array}$ \\
\hline \begin{tabular}{|l|} 
P (phos- \\
phate)
\end{tabular} & $\begin{array}{l}\text { HAP noncalcined } \\
\text { HAP calcined } \\
\text { HAPc-5\%Sr noncalcined } \\
\text { HAPc- } 5 \% \text { Sr calcined } \\
\text { HAPc- } 10 \% \text { Sr noncalcined } \\
\text { HAPc- } 10 \% \text { Sr calcined }\end{array}$ & Water & $\begin{array}{l}10.5 \pm 1.4 \\
21.7 \pm 3.9 \\
14.0 \pm 1.2 \\
18.6 \pm 2.3 \\
13.0 \pm 1.4 \\
13.6 \pm 2.0\end{array}$ & $\begin{array}{l}4.44 \pm 0.27 \\
6.4 \pm 0.7 \\
6.98 \pm 0.22 \\
9.51 \pm 0.44 \\
4.21 \pm 0.27 \\
4.62 \pm 0.37\end{array}$ & $\begin{array}{l}0.9746 \\
0.9133 \\
0.9932 \\
0.9852 \\
0.9723 \\
0.9559\end{array}$ \\
\hline $\mathrm{Mg}^{2+}$ & $\begin{array}{l}\text { HAPc-5\%Sr noncalcined } \\
\text { HAPc- } 5 \% \text { Sr calcined } \\
\text { HAPc- } 10 \% \text { Sr noncalcined } \\
\text { HAPC- } 10 \% \text { Sr calcined }\end{array}$ & Water & $\begin{array}{l}4.9 \pm 0.7 \\
3.7 \pm 0.8 \\
4.2 \pm 0.6 \\
4.2 \pm 0.6\end{array}$ & $\begin{array}{l}1.27 \pm 0.14 \\
1.73 \pm 0.14 \\
1.14 \pm 0.20 \\
1.26 \pm 0.11\end{array}$ & $\begin{array}{l}0.9208 \\
0.9540 \\
0.9426 \\
0.9481\end{array}$ \\
\hline $\mathrm{Sr}^{2+}$ & $\begin{array}{l}\text { HAPc-5\%Sr noncalcined } \\
\text { HAPc- } 5 \% \text { Sr calcined } \\
\text { HAPc- } 10 \% \text { Sr noncalcined } \\
\text { HAPC- } 10 \% \text { Sr calcined }\end{array}$ & Water & $\begin{array}{l}2.68 \pm 0.20 \\
3.81 \pm 0.28 \\
3.88 \pm 0.27 \\
5.99 \pm 0.36\end{array}$ & $\begin{array}{l}0.538 \pm 0.038 \\
0.690 \pm 0.053 \\
0.71 \pm 0.05 \\
0.74 \pm 0.07\end{array}$ & $\begin{array}{l}0.9653 \\
0.9606 \\
0.9648 \\
0.9416\end{array}$ \\
\hline $\mathrm{Sr}^{2+}$ & $\begin{array}{l}\text { HAPc-5\%Sr noncalcined } \\
\text { HAPc-5\%Sr calcined } \\
\text { HAPC- } 10 \% \text { Sr noncalcined } \\
\text { HAPC- } 10 \% \text { Sr calcined }\end{array}$ & SBF & $\begin{array}{l}5.73 \pm 0.11 \\
7.33 \pm 0.32 \\
7.2 \pm 0.6 \\
8.5 \pm 0.7\end{array}$ & $\begin{array}{l}0.315 \pm 0.021 \\
0.40 \pm 0.06 \\
0.49 \pm 0.11 \\
0.59 \pm 0.14\end{array}$ & $\begin{array}{l}0.9704 \\
0.8588 \\
0.7205 \\
0.7114\end{array}$ \\
\hline
\end{tabular}

In Table 2, the same parameters of eq. (2) as in Table 1 are given, for the cumulated dynamic ion release in days 1-7.

Here the linearity of the relation (2) for days 1-7 is very good, as seen also in Figure 3; all the coefficients of determination are above 0.95, most of them about 0.99 . 
Table 2. Application of equation (2) for ions release from HAPs in water and in SBF in simulated dynamic conditions (days 1-7); noncalc stands for noncalcined.

\begin{tabular}{|c|c|c|c|c|c|}
\hline Ion & Sample & $\begin{array}{l}\text { Me- } \\
\text { dium }\end{array}$ & $\begin{array}{c}a \\
(\mathrm{mg} / \mathrm{L})\end{array}$ & $\begin{array}{c}\mathrm{K} \\
\mathrm{mg} \mathrm{L}^{-1} \mathrm{~d}^{-1 / 2}\end{array}$ & $r^{2}$ \\
\hline $\mathrm{Ca}^{2+}$ & $\begin{array}{l}\text { HAP noncalcined } \\
\text { HAP calcined } \\
\text { HAPc- } 5 \% \text { Sr noncalc. } \\
\text { HAPc- } 5 \% S r \text { calcined } \\
\text { HAPc- } 10 \% S r \text { noncalc. } \\
\text { HAPc- } 10 \% S r \text { calcined }\end{array}$ & Water & $\begin{array}{l}-0.8 \pm 0.7 \\
-2.8 \pm 1.7 \\
-3.7 \pm 2.1 \\
-3.0 \pm 1.7 \\
-10.33 \pm 0.27 \\
-7.32 \pm 0.26\end{array}$ & $\begin{array}{l}9.14 \pm 0.40 \\
11.1 \pm 0.9 \\
14.5 \pm 1.1 \\
17.3 \pm 0.9 \\
16.67 \pm 0.13 \\
18.07 \pm 0.13\end{array}$ & $\begin{array}{l}0.9867 \\
0.9556 \\
0.9587 \\
0.9803 \\
0.9996 \\
0.9997\end{array}$ \\
\hline $\begin{array}{l}P \text { (phos- } \\
\text { phate) }\end{array}$ & $\begin{array}{l}\text { HAP noncalcined } \\
\text { HAP calcined } \\
\text { HAPc- } 5 \% \text { Sr noncalc. } \\
\text { HAPc- } 5 \% \text { Sr calcined } \\
\text { HAPC- } 10 \% S r \text { noncalc. } \\
\text { HAPc- } 10 \% S r \text { calcined }\end{array}$ & Water & $\begin{array}{l}-18.0 \pm 1.8 \\
-11.9 \pm 3.9 \\
-19.9 \pm 4.5 \\
-16.8 \pm 4.0 \\
-21.7 \pm 3.0 \\
=23.8 \pm 3.2\end{array}$ & $\begin{array}{l}30.2 \pm 0.9 \\
37.4 \pm 2.0 \\
43.3 \pm 2.2 \\
47.3 \pm 2.0 \\
38.9 \pm 1.5 \\
42.1 \pm 1.6\end{array}$ & $\begin{array}{l}0.9948 \\
0.9837 \\
0.9841 \\
0.9892 \\
0.9913 \\
0.9913\end{array}$ \\
\hline $\mathrm{Mg}^{2+}$ & $\begin{array}{l}\text { HAPc- } 5 \% \text { Sr noncalc. } \\
\text { HAPc- } 5 \% \text { Sr calcined } \\
\text { HAPc- } 10 \% \text { Sr noncalc. } \\
\text { iHAPC- } 10 \% \text { Sr calcined }\end{array}$ & Water & $\begin{array}{l}-5.5 \pm 1.5 \\
-4.9 \pm 0.5 \\
-5.89 \pm 0.37 \\
-7.41 \pm 0.49\end{array}$ & $\begin{array}{l}12.0 \pm 0.8 \\
9.86 \pm 0.27 \\
10.38 \pm 0.18 \\
11.78 \pm 0.24\end{array}$ & $\begin{array}{l}0.9759 \\
0.9956 \\
0.9956 \\
0.9974\end{array}$ \\
\hline $\mathrm{Sr}^{2+}$ & $\begin{array}{l}\text { HAPc- } 5 \% \text { Sr noncalc. } \\
\text { HAPc- } 5 \% \text { Sr calcined } \\
\text { HAPc- } 10 \% \text { Sr noncalc. } \\
\text { HAPC- } 10 \% \text { Sr calcined }\end{array}$ & Water & $\begin{array}{l}-5.62 \pm 0.29 \\
-3.63 \pm 0.11 \\
-6.68 \pm 0.21 \\
-8.11 \pm 0.25\end{array}$ & $\begin{array}{l}8.30 \pm 0.15 \\
7.76 \pm 0.06 \\
10.66 \pm 0.10 \\
14.24 \pm 0.13\end{array}$ & $\begin{array}{l}0.9981 \\
0.9997 \\
0.9994 \\
0.9995\end{array}$ \\
\hline $\mathrm{Sr}^{2+}$ & $\begin{array}{l}\text { HAPc- } 5 \% \text { Sr noncalc. } \\
\text { HAPc- } 5 \% \text { Sr calcined } \\
\text { HAPc- } 10 \% \text { Sr noncalc. } \\
\text { HAPC- } 10 \% S r \text { calcined }\end{array}$ & SBF & $\begin{array}{l}-8.86 \pm 20.24 \\
-9.83 \pm 0.48 \\
-11.53 \pm 0.42 \\
-13.5 \pm 0.62\end{array}$ & $\begin{array}{l}14.75 \pm 0.12 \\
17.16 \pm 0.24 \\
17.13 \pm 0.21 \\
19.99 \pm 0.31\end{array}$ & $\begin{array}{l}0.9996 \\
0.9988 \\
0.9991 \\
0.9985\end{array}$ \\
\hline
\end{tabular}

\section{CONCLUSIONS}

Considering the validity ranges of the Higuchi model for the ions release from the investigated HAPs, we can affirm that, while diffusion is important throughout the entire process of ion release in static conditions, from day 1 to 90 , dissolution has also a significant contribution in the initial phase of the process. After the dissolution of the outer, more soluble, shell of particles, the internal diffusion of ions from the bulk to the interface with 
the immersion medium will be the main process. Moreover, in time a saturation of the solution is approached due to the low solubility, so diffusion remains predominant.

In simulated dynamic condition, when the immersion liquid is daily renewed, no saturation could occur, so both dissolution and diffusion contribute to the ion release.

Nonetheless, the ions exchange process cannot be ruled out, both in static and in simulated dynamic conditions.

\section{EXPERIMENTAL SECTION}

The synthesis of HAP and multi-substituted HAPs (HAPc- $5 \% \mathrm{Sr}$ and HAPc-10\%Sr, both containing $1.5 \mathrm{wt} \% \mathrm{Mg}, 0.2 \mathrm{wt} \% \mathrm{Zn}, 0.2 \mathrm{wt} \% \mathrm{Si}$ and 5 $\mathrm{wt} \%$, respectively $10 \mathrm{wt} \% \mathrm{Sr}$ ) was carried out as shown elsewhere $[2,6,7$, 11] by a wet chemical method. Shortly, an aqueous solution containing the calculated amounts of cations $\left(\mathrm{Ca}^{2+}, \mathrm{Mg}^{2+}, \mathrm{Zn}^{2+}, \mathrm{Sr}^{2+}\right.$ as nitrates) and another solution for the anions phosphate and silicate (containing $\left(\mathrm{NH}_{4}\right)_{2} \mathrm{HPO}_{4}$ and tetraethyl orthosilicate, TEOS) were prepared and ammonia solution was added to assure an alkaline $\mathrm{pH}$ (11.5). The solutions were mixed at room temperature, to assure a stoichiometric ratio cations/anions $=5 / 3$, and after maturation the precipitate was separated by filtration. Two series of powdered samples were used: lyophilized (noncalcined) and calcined at $300^{\circ} \mathrm{C}(1 \mathrm{~h})$.

The ion release was studied in ultrapure deionized water $(\mathrm{pH} \mathrm{5.6)}$ and in simulated body fluid (Kokubo's SBF) [47] containing (mmol/L): $\mathrm{Na}^{+}$ (142.0); $\mathrm{K}^{+}(5.0) ; \mathrm{Mg}^{2+}(1.5) ; \mathrm{Ca}^{2+}(2.5) ; \mathrm{Cl}^{-}$(147.8); $\mathrm{HCO}_{3}^{-}$(4.2); $\mathrm{HPO}_{4}{ }^{2-}$ (1.0); $\mathrm{SO}_{4}{ }^{2-}(0.5)$, buffered at the physiologic $\mathrm{pH} 7.40$ at $37{ }^{\circ} \mathrm{C}$, with tris(hydroxymethyl)amino methane and hydrochloric acid. Samples of 0.15 $\mathrm{g}$ for each of the 6 solid HAPs were soaked in $15 \mathrm{~mL}$ liquid (HAPs content $10 \mathrm{~g} / \mathrm{L}$ ) at $37^{\circ} \mathrm{C}$ [11]. For the study in static conditions, these samples were kept in closed flasks at $37^{\circ} \mathrm{C}$ for $1 ; 3 ; 7 ; 14 ; 21 ; 30 ; 60$, and 90 days, and afterwards the filtrated solutions were analyzed. In simulated dynamic conditions (7 days) the immersion liquid for each sample was analyzed daily and then changed with the same volume of fresh liquid.

In the filtrates, the $\mathrm{Ca}, \mathrm{Mg}, \mathrm{Sr}, \mathrm{Zn}, \mathrm{P}$ and $\mathrm{Si}$ content was measured with an inductively coupled plasma optical emission spectrometer (ICP-OES) OPTIMA 5300DV (Perkin-Elmer, USA), using calibration solutions prepared from multi-element IV storage solutions $[11,27]$. The results were calculated as $\mathrm{mg} / \mathrm{L}(\mathrm{ppm})$. $\mathrm{Zn}$ and Si could not be determined in the solutions, because their concentration was under the limit of quantification of the method. 
The graphics and the data analysis for linear fitting to obtain the regression lines and their parameters were performed by means of the Origin $8.5^{\circledR}$ software from OriginLab ${ }^{\circledR}$.

\section{ACKNOWLEDGEMENTS}

This work was supported by grants of the Ministry of Research, Innovation and Digitization, CNCS/CCCDI-UEFISCDI, project number 186 and 481, within PNCDI III.

\section{REFERENCES}

1. P. T. Frangopol; A. Mocanu; V. Almasan; C. Garbo; R. Balint; G. Borodi; I. Bratu; O. Horovitz; M. Tomoaia-Cotisel; Rev. Roum. Chim., 2016, 61(4-5), 337-344.

2. E. Forizs; F. Goga; A. Avram; A. Mocanu; I. Petean; O. Horovitz; M. TomoaiaCotisel; Studia UBB Chemia; 2017, 62(4, Tom I), 173-180.

3. S. Rapuntean; P. T. Frangopol; I. Hodisan; Gh. Tomoaia; D. Oltean-Dan; A. Mocanu; C. Prejmerean; O. Soritau; L. Z. Racz; M. Tomoaia-Cotisel; Rev. Chim. (Bucharest), 2018, 69(12), 3535-3544.

4. Gh. Tomoaia; M. Tomoaia-Cotisel; L.-B. Pop; A. Pop; O. Horovitz; A. Mocanu; N. Jumate; L.-D. Bobos; Rev. Roum. Chim. 2011, 56(10-11), 1039-1046.

5. Gh. Tomoaia; O. Soritau; M. Tomoaia-Cotisel; L.-B. Pop; A. Pop; A. Mocanu; O. Horovitz; L.-D. Bobos; Powder Technol., 2013, 238, 99-107.

6. Gh. Tomoaia; M. Tomoaia-Cotisel; L.B. Pop; A. Mocanu; A. Pop; Nanopowders of hydroxyapatite and its substituted derivatives with medical applications and their fabrication procedure, Romanian Patent, OSIM, Bucharest, Romania, no. 125817 B1, BOPI, 2013, 6, 123.

7. F. Goga; E. Forizs; A. Avram; A. Rotaru; A. Lucian; I. Petean; A. Mocanu; M. Tomoaia-Cotisel; Rev. Chim. (Bucharest), 2017, 68(6), 1193-1200.

8. Gh. Tomoaia; L.B. Pop; I. Petean; M. Tomoaia-Cotisel; Mater. Plast., 2012, 49(1), 48-54.

9. Gh. Tomoaia; A. Mocanu; I. Vida-Simiti; N. Jumate; L.-D. Bobos; O. Soritau; M. Tomoaia-Cotisel; Mater. Sci. Eng. C, 2014, 37, 37-47.

10. D. Oltean-Dan; G. B. Dogaru; M. Tomoaia-Cotisel; D. Apostu; A. Mester; H. R. C. Benea; M. G. Paiusan; E. M. Jianu; A. Mocanu; R. Balint; C. O. Popa; C. Berce; G. I. Bodizs; A. M. Toader; Gh. Tomoaia; Int. J. Nanomed., 2019, 14, 5799-5816.

11. C. Garbo; J. Locs; M. D’Este; G. Demazeau; A. Mocanu; C. Roman; O. Horovitz; M. Tomoaia-Cotisel; Int. J. Nanomed., 2020, 15, 1037-1058.

12. C. Lindahl; W. Xia; J. Lausmaa; H. Engqvist; Biomed. Mater., 2012, 7, 045018; doi:10.1088/1748-6041/7/4/045018. 
AURORA MOCANU, PETRE T. FRANGOPOL, REKA BALINT, OANA CADAR, IULIA MARIA VANCEA, ROZALIA MINTĂU, OSSI HOROVITZ, MARIA TOMOAIA-COTISEL

13. B. Colovic; S. Pasalic; V. Jokanovic; Ceram. Int., 2012, 38(8), 6181-6189.

14. M.-S. Wu; W. I. Higuchi; J. L. Fox; M. Friedman; J. Dent. Res., 1976, 55(3), 496-505.

15. Q. Liu; W. Guo; M. Yang; K. Wang; W. Liu; F. Wu; Adv. Polym. Technol., 2019, Article ID 9562437; https://doi.org/10.1155/2019/9562437.

16. M. Rohnke; S. Pfitzenreuter; B. Mogwitz; A. Henß; J. Thomas; D. Bieberstein; T. Gemming; S. K. Otto; S. Ray; M. Schumacher; M. Gelinsky; V. Alt; J. Control. Release, 2017, 262, 159-169.

17. A. Mocanu; G. Furtos; S. Rapuntean; O. Horovitz; C. Flore; C. Garbo; A. Danisteanu; Gh. Rapuntean; C. Prejmerean; M. Tomoaia-Cotisel; Appl. Surf. Sci., 2014, 298, 225-235.

18.Gh. Tomoaia; A. Mocanu; L.-D. Bobos; L.-B. Pop; O. Horovitz; M. TomoaiaCotisel; Studia UBB Chemia, 2015, 60(3), 265-272.

19.C. Garbo; M. Sindilaru; A. Carlea; Gh. Tomoaia; V. Almasan; I. Petean; A. Mocanu; O. Horovitz; M. Tomoaia-Cotisel; Particul. Sci. Technol, 2017, 35(1), 29-37.

20.M.-P. Ginebra; C. Canal; M. Espanol; D. Pastorino; E. B. Montufar; Adv. Drug Deliv. Rev, 2012, 64(12), 1090-1110.

21.M. H. Alkhraisat; C. Rueda; J. Cabrejos-Azama; J. Lucas-Aparicio; F. T. Mariño; J. Torres García-Denche; L. B. Jerez; U. Gbureck; E. L. Cabarcos; Acta Biomater., 2010, 6(4), 1522-1528.

22. U. Gbureck; E .Vorndran; J. E. Barralet. Acta Biomater., 2008, 4(5), 1480-1486.

23. E. Vidal; J. Buxadera-Palomero; C. Pierre; J. M. Manero; M.-P. Ginebra; S. Cazalbou; C. Combes; E. Rupérez; D. Rodríguez; Surf. Coat. Technol., 2019, 358; 266-275.

24. G. R. Mahdavinia; M. H. Karimi; M. Soltaniniya; B. Massoumi; Int. J. Biol. Macromol., 2019, 126, 443-453.

25. G. Vidhya; G. S. Kumar; V. S. Kattimani; E. K. Girija; Mater. Today: Proceedings, 2019, 15(2), 344-352.

26. C. Luo; S. Wu; J. Li; X. Li; P. Yang; G. Li; Int. J. Biol. Macromol., 2020, 155, 174-183.

27. A. Mocanu; O. Cadar; P. T. Frangopol; I. Petean; Gh. Tomoaia; G. A. Paltinean; C. P. Racz; O. Horovitz; M. Tomoaia-Cotisel; Roy. Soc. Open Sci., 2021, 8(1), 201785; https://doi.org/10.1098/rsos.201785.

28. O. Cadar; R. Balint; Gh. Tomoaia; D. Florea; I. Petean; A. Mocanu; O. Horovitz; M. Tomoaia-Cotisel; Studia UBB Chemia, 2017, 62 (4; Tom II), 269-281.

29. T. Higuchi; J. Pharm. Sci., 1963, 52(12), 1145-1149.

30. S. Dash; P. N. Murthy; L. Nath; P. Chowdhury; Acta Pol. Pharm., 2010, 67(3), 217-223.

31. J. Siepmann; N. A. Peppas; Int. J. Pharm., 2011, 418(1), 6-12.

32. Y. Fu; W. J. Kao;. Expert Opin. Drug Deliv.; 2010, 7(4), 429-444.

33. M. Golshan; M. Salami-Kalajahi; H. Roghani-Mamaqani; M. Mohammadi;. Polymer, 2017, 117, 287-294.

34. R. Gouda; H. Baishya; Z. Qing; J. Develop. Drugs, 2017, 6(2), 1000171; https://doi.org/10.4172/2329-6631.1000171. 
35. G. Nikravan; V. Haddadi-Asl; M. Salami-Kalajahi; e-Polymers, 2019, 19(1), 203-214.

36. H.-G. Lee; Y.-S. Park; J.-H. Jeong; Y.-B. Kwon; D. H. Shin; J.-Y. Kim; Y.-S. Rhee; E.-S. Park; D.-W. Kim; C.-W. Park; Drug Des., Devel. Ther., 2019, 13, 2459-2474.

37. M. M. Leena; M. G. Antoniraj; J. A. Moses; C. Anandharamakrishnan; J. Drug Deliv. Sci. Technol., 2020, 57, 101678; https://doi.org/10.1016/j.jddst.2020. 101678.

38. S. Bose; S. Tarafder; Acta Biomater., 2012, 8(4), 1401-1421.

39. M. M. Mailafiya; K. Abubakar; A. Danmaigoro; S. M. Chiroma; E. B. A. Rahim; M. A. M. Moklas; Z. A. B. Zakaria; Biomed. Res. Ther., 2019, 6(12), 35183540.

40. S. Mondal; G. Hoang; P. Manivasagan; H. Kim; J. Oh; Ceram. Int., 2019, 45(14), 17081-17093.

41. E. Landi; A. Tampieri; G. Celotti; S. Sprio; M. Sandri; G. Logroscino; Acta Biomater., 2007, 3(6), 961-969.

42. E. Boanini; M. Gazzano; A. Bigi; Acta Biomater., 2010, 6(6), 1882-1894.

43. N. C. Andres; N. L. D'Elía; J. M. Ruso; A. E. Campelo; V. L. Massheimer; P. V. Messina; ACS Appl. Mater. Interfaces, 2017, 9(18), 15698-15710.

44. S. Chen; Y. Shi; X. Zhang; J. Ma; J. Biomed Mater Res A., 2019, 107(11), 2512-2521.

45. J. Beuvelot; Y. Mauras; G. Mabilleau; H. Marchand-Libouban; D. Chapparda; Dig. J. Nanomater. Biostruct., 2013, 8(1), 207-217.

46. S. V. Dorozhkin; J. Colloid. Interf. Sci., 1997, 191(2), 489-497.

47. T. Kokubo; Biomaterials, 1991, 12(2), 155-163. 